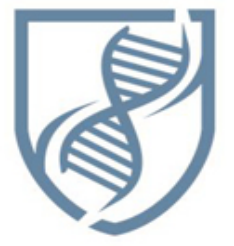

Journal of Bioscience and Applied Research
JBAAR

WWW.JBAAR.ORG

\title{
Gasoline induced pulmo- oxidative damage in mice model
}

\author{
Awatef Ali $^{1}$,Nawal El-Ghazaly ${ }^{2}$, Samir Dekinesh ${ }^{3}$, Sanaa Kabiel $^{4}$, Azza Sedky $^{5}$ \\ 1,2,3,5 Zoology department -Faculty of Science-Alexandria University-Egypt \\ ${ }^{4}$ Genetic \&Biotechnology institute-City of Scientific Researches-Alexandria University- Egypt \\ Corresponding author e.mail.Awatef-Ali@hotmail.com
}

\begin{abstract}
The present work aims to evaluatethe cytotoxic effects on lung cells exerted by gasoline. 60 male albino mice were used in the present experiment, divided equally into 3 groups: first group (control) was left access to fresh air, second group (experimental) was subjected to gasoline 80vapor/1h./day and third group (experimental) was subjected to gasoline 90-vapor/1h./day along eight consecutive weeks. The study comprises determination of body weight, bioaccumulation of some heavy metals ,histological and ultra-changes . Histological changes increased according to duration of exposure as, infiltration of inflammatory cells, detachment and necrosis of the epithelial cells .The electron micrographs revealed dilatation of the smooth endoplasmic reticulum, loss of the secretory granules in the Clara cells and loss of cilia in the ciliated cells that exhibited bleb formation. Necrotic type II pneumocytes, exhibited vacuolation, fragmentation of the rough endoplasmic reticulum,mitochondrial degeneration, nuclear alterations, degeneration of lamellar bodies and microvillar atrophy. In conclusion, gasoline vapour inhalation induced lung tissue injury and cellular damage concomitant with impairment of the lung antioxidant defense system. These effects were more pronounced with the unleaded than with the leaded gasoline.
\end{abstract}

Key words:Gasoline, Mice Model, Bioaccumulation, weight, Histology.

\section{Introduction}

Gasoline is one of the largest volume commercial products in the world (Cutler et al., 2007).It is a complex substance of variable composition depending on the source of raw material (crude oil ), the refining processes, performance specification ,season and other factors (Grebic et al.,2007).
Nagy et al. (2004) stated that crude oil can basically be divided into two distinct groups: naphthenic and paraffinic oils. Naphthenic oils contain complex mixture of hydrocarbons and low concentrations of alkanes (branched and straight chain), which provides them with such properties as low viscosity even at low temperatures. The ring structures in naphthenic oils can be of five, six and seven carbon atoms with six being predominant. Paraffinic oils, on the other hand, contain predominantly alkanes and have high viscosity.

Emissions of gasoline and its combustion products are considered major air pollutants with adverse effects on the respiratory system (Ahmed et al., 2011).Gasoline can be modified to reduce pollution and improve the fuel combustion by adding components containing oxygen. The most widely used oxygenate is Methyl Tertiary-Butyl Ether (MTBE), whereas methanol and ethanol are possible substitutes (Lin et al., 2005)

Management of gasoline toxicity depends on the way of exposure (Ata et al., 2012). Fever and leukocytosis are common after intoxication. Pulmonary involvement is the most common organ damage. The risk of pulmonary toxicity is determined by volatility, viscosity and surface tension. Capillary distension, alveolar hemorrhage, vascular Bhrbmbosis and bronchial necrosis lead to pulmonary injury(Domej et al.,2007).It was generally observed that inhalation of high concentrations of gasoline for a long time like 3 months may be deleterious to health (Monago et al.,2011)

Very little attention has been paid to the changes induced on non-cutaneous organs by inhalation exposure with regard to the cellular structure and ultra-levels. The present experiments were designed to study the effect of gasoline on lung cells of male Swiss albino mice (Mus 
musculus).Also, detected the proinflammatory functional responses exerted by gasoline after 4 and 8 weeks.

\section{Materials and Methods}

In the present study 60 healthy specific pathogen free, male mice (10 w., 25-30 g.) were used. The mice were obtained from the animal house -Faculty of Medicine, Alexandria University, reared in metal cages $(30 \mathrm{~cm}$ length, $20 \mathrm{~cm}$ width and $15 \mathrm{~cm}$ high) substrated with wood shaving and acclimatized for one week before the initiation of the experiments, under normal laboratory conditions. Animals were allowed free access of a standard balanced laboratory diet (wheat, milk and carrot) and tap water. Two types of gasoline (unleaded -octane 80 and leaded -octane 90) were used (It is a coloured liquid with a distinctive odor).

Mice were divided into three groups (20 mice each).GI (control group) where animal were allowed to respire only fresh air, GII were daily exposed to vapour of gasoline solution of octane number 90, GIII were daily exposed to vapour of gasoline solution of octane number 80 by soaking $5 \mathrm{ml}$ of gasoline in a piece of cotton wool which was plastered on one end of the animal cages. The vapour was allowed to mix with the ambient air of each animal cage for one hour. The piece of soaked cotton was daily changed (Ugwokeet al. 2005).The experiment extended 8 weeks.All procedures performed in studies involving animals were in accordance with the ethical standards of college of Science-Alexandria University.

\section{Determination of body weight:}

Themean of body weights of five mice from each group were determined at the beginning (initial body weight, IBW) and after 4, 8 weeks (final body weight, FBW).

Percentage weight increase $=\frac{\mathrm{FBW}-\mathrm{IBW}}{\mathrm{IBW}} \times 100$

(Ubohet al., 2008)

Determination of bioaccumulation of some heavy metalsafter exposure to both types of gasoline $(90$ and 80):

The concentration of lead, cadmium and nickel were determined in the lung by using electron dispersive X-ray apparatus attached to scanning electron microscope (Leo UIF: Leo438VP) - Faculty of Science, Alexandria University.

\section{Microscopical studies:}

After 4, 8 weeks, the1/2 left lung of each animal carefully was dissected out andfixed at room temperature overnight in $10 \%$ formalin solution then process to be stained with Haematoxylin and Eosin (Bancroft and Gamble ,2002). The prepared slides were examined under light microscope using objective lens power (X10,X40,X100).

After 8 weeks, the other $1 / 2$ left lung was cut into small pieces $(0.1 \mathrm{~mm}$ in thickness) and fixed in $3 \%$ glutaraldehyde fixative for electron microscopy processing and examined using Joel $100 \mathrm{CX}$ transmission electron microscope of the Faculty of Science, Alexandria University

\section{Statistical analysis:}

SPSS program was used to evaluate the significance of the difference between mean value of the measured parameters in the respective tested groups and control-group. A significant change was accepted at $\mathrm{P} \leq 0.05$.

\section{Results}

\section{Change in body weight of mice:}

After gasoline exposure for 4,8 weeks ,the percentage body weight increase in alltreated groupswere lesser (3.23\%-4 w. $-90 \& 80),(5.51 \%-8$ w. -90$),(5.03 \%-8$ w. 80$)$ than control(4.08\% -4w.), (9.12\%-8 w.)respectively(Table 1).

\section{Results of bioaccumulation of some heavy metals after} exposure to both types of gasoline (90 and 80$)$ :

There was significant difference between the lead, cadmium and nickel concentrations in lung of control mice and those inhaled gasoline 80 or 90 for 4 and 8 weeks respectively $(\mathrm{F}=29.848$ and $\mathrm{P}=0.001),(\mathrm{F}=11.283$ and $\mathrm{P}=$ $0.001)$ and $(\mathrm{F}=19.029$ and $\mathrm{P}=0.001)($ Table 2$)$.

\section{Light microscope observations}

Figure (1) revealed the normal structure of lung including respiratory bronchiole with large central lumen, alveolar duct processing into alveolar sacs or alveoli with small central lumen. The respiratory bronchiole appeared lined with folded simple columnar epithelium with basal oval nuclei and short cuboidal Clara cells with large round nuclei. This lining layer is covered with a thin layer of smooth muscle cells having flat central nuclei. The alveoli appeared well preserved and separated by alveoli wall (Figure2).

Haematoxylin and eosin stained sections of mice lung inhaled gasoline 90 for 4 weeks revealed the presence of consolidated inflammatory cell. The respiratory bronchiole suffered from direct damage which appeared as cellular debris in its lumen detached from its lining layer. There were emphysema due to fusion of enlarged alveoli with thin wall and alveolar hemorrhage (Figure 3). The lining layer of the respiratory bronchiole contained Clara cells with irregular nuclei instead of round one and the alveolar wall became thinner (Figure 4). With extended treatment until 8 weeks more alternations were observed in lung architecture including hemorrhage, alveoli with emphysema and thick alveolar walls due to the proliferation of alveolar wall cells (Figure 5). The respiratory bronchiole contained cellular debris with degenerated Clara cells (Figure 6).

In lung of miceinhaled gasoline 80 for 4 weeks elicited per vascular inflammatory cellular infiltration,congestedrespiratory bronchiole with exfoliated epithelial cells and alveoli with emphysema(Figure 7). Also, there was per vascular fibrous mass replacing the alveoli structures and thick alveolar wall (Figure 8). 
Table (1): Percentage of body weight increase in male mice

\begin{tabular}{|c|c|c|c|}
\hline \multirow{2}{*}{ Experimental mice } & \multicolumn{2}{|c|}{ Average body weight (gm.) } & \multirow{2}{*}{$\begin{array}{l}\text { Percentage body weight increase } \\
(\%)\end{array}$} \\
\hline & Initial & final & \\
\hline Control/4w. & $27.4 \pm 0.8$ & $28.52 \pm 0.9$ & $4.08 \%$ \\
\hline Mice inhaled gasoline 90/4w. & $27.2 \pm 0.7$ & $28.08 \pm 0.7$ & $3.23 \%$ \\
\hline Mice inhaled gasoline $80 / 4 w$. & $27.8 \pm 0.6$ & $28.7 \pm 0.3$ & $3.23 \%$ \\
\hline Control/8w. & $27.4 \pm 0.8$ & $29.9 \pm 0.8$ & $9.12 \%$ \\
\hline Mice inhaled gasoline 90/8w. & $27.2 \pm 0.7$ & $28.7 \pm 0.7$ & $5.51 \%$ \\
\hline Mice inhaled gasoline $80 / 8 \mathrm{w}$. & $27.8 \pm 0.6$ & $29.2 \pm 0.7$ & $5.03 \%$ \\
\hline
\end{tabular}

Table (2): $\quad$ Bioaccumulation of some heavy metals (\%total) in lungs

\begin{tabular}{|c|c|c|c|}
\hline Experimental group & Lead & Cadmium & Nickel \\
\hline Control & $0.0^{c} \pm 0.0$ & $0.10^{b} \pm 0.0$ & $0.07^{c} \pm 0.07$ \\
\hline Gasoline 90/4 w. & $12.0^{b} \pm 0.15$ & $0.40^{b} \pm 0.06$ & $0.33^{b c} \pm 0.07$ \\
\hline Gasoline 90/8 w. & $21.7^{b} \pm 0.35$ & $0.97^{b} \pm 0.12$ & $0.37^{b} \pm 0.07$ \\
\hline Gasoline 80/4 w. & $43.57^{\mathrm{a}} \pm 0.41$ & $0.93^{a} \pm 0.03$ & $0.60^{b} \pm 0.06$ \\
\hline Gsoline 80/8 w. & $34.13^{a} \pm 0.46$ & $1.70^{a} \pm 0.12$ & $2.30^{\mathrm{a}} \pm 0.26$ \\
\hline$\overline{(\mathbf{p})}$ & $29.848^{*}(<0.001)$ & $111.283^{*}(0.001)$ & $19.029^{*}(<0.001)$ \\
\hline
\end{tabular}

\section{F: F test $\mathrm{f}$ (ANOVA)}

$\mathrm{p}$ : $\mathrm{p}$ value for $\mathrm{F}$ test (ANOVA)

Different superscripts are significant. *: Statistically significant at $\mathrm{p} \leq 0.05$

Lung of mice inhaled gasoline 80 for 8 weeks illustrate of cytoplasm of type I pneumocyte, fused membrane and remarkable signs of deterioration, there was a respiratory cytoplasm of capillary endothelial cell (Fig.12).

bronchiole with enlarged respiratory epithelial fold nearby Type II pneumocyte (P2) contained lamellar bodies, oval dilated blood vessel with statis blood cells, regions of per mitochondria, secondary lysosomes, irregular plump large vascular inflammatory cell infiltrate, thick alveolar wall and nucleus with disperses chromatin and prominent nucleolus alveoli with emphysema (Figure 9). Enlarged part of in its cytoplasm (Fig.13). Enlarged part of figure 13 respiratory bronchiole showed Clara cells with shrinked showed also free ribosomes, rough endoplasmic reticulum nuclei, some detached epithelialcellsexfoliatedinto the lumen. and multi-Golgi (Fig.14).

In addition, the alveolar wall appeared with variable Lung sections of mouse inhaled gasoline 90 for 8 weeks thickness(Figure 10).

\section{Transmission electron microscopical observations}

Examination the sections of control -grouprevealed that the lung alveolar region contained capillaries that made up the bulk of the alveolar wall branching and anastomosing to crest a basket-like arrangement around each alveolus. The lumen of capillary included the nucleus of its lining endothelial cell (Fig.11). showed thin alveolar septum arised from thin cytoplasm of both type I pneumocyte and capillary endothelial cell(Fig.15). The type II pneumocyte had increased number of destructed lamellar bodies, irregular nucleus, pleomorphic and fused mitochondria (Fig.16). Segmented mitochondria and pyknotic nuclei with prominent heterochromatin are also seen in type II pneumocyte (Fig.17).In addition, hypertrophied Golgi apparatus, cytoplasmic vacuoles, nucleus with wide nuclear pore and The cytoplasm of type I pneumocyte (P1) which cover dilated nuclear envelope were seen (Fig.18).

most of the alveolar surface and of capillary endothelial The electron preparation of lung sections of mouse inhaled cell are both extremely attenuated. The component of gasoline 80 for 8 weeks revealed the presence of secretion alveolar septum between blood and alveolar air consisting and cellular debris in some alveoli (Fig.19). The capillary 


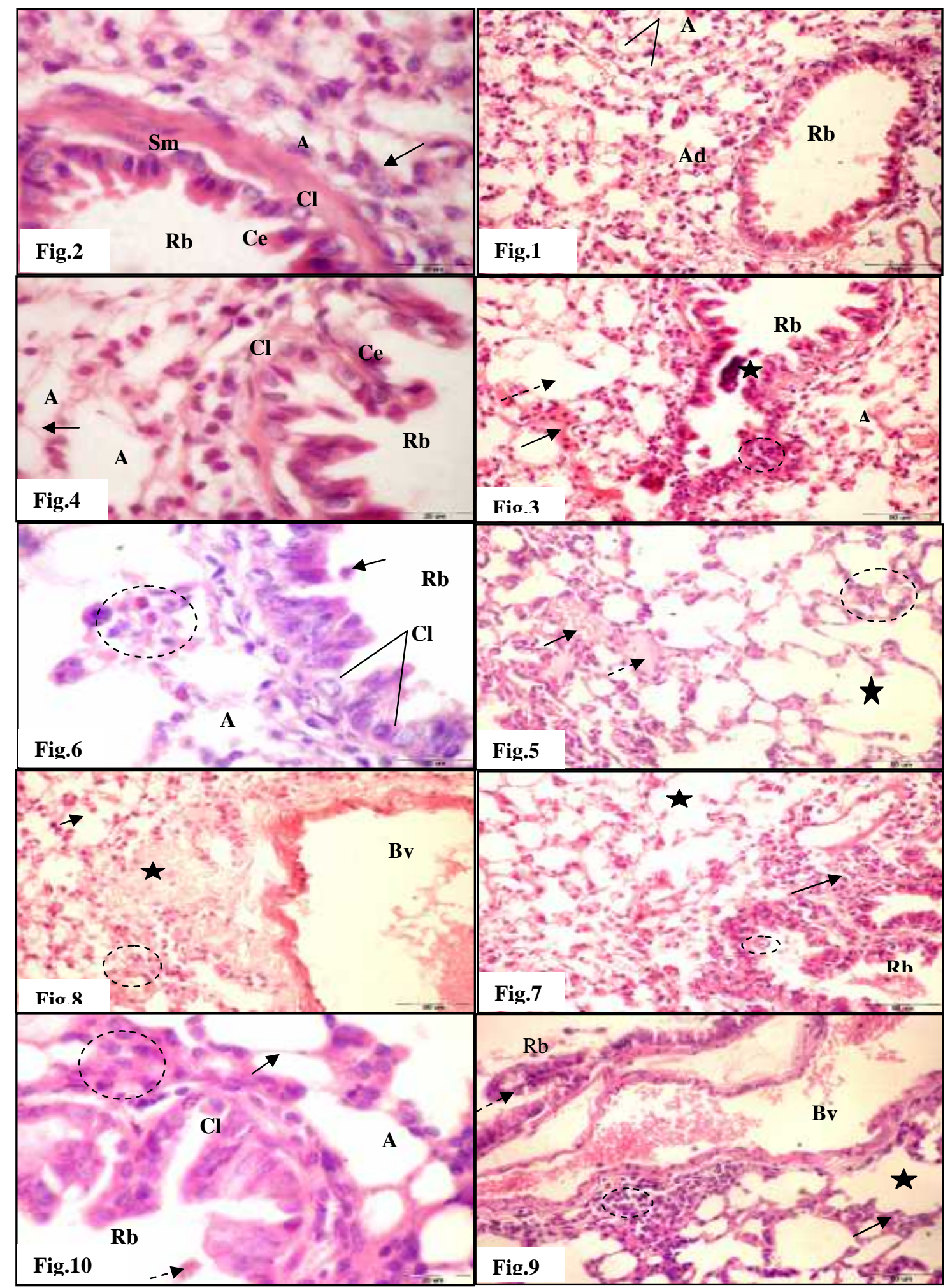

Figs. (1,2): Light micrograph of lung sections of control mouse showing:

(1) Respiratory bronchiole ( $\mathrm{Rb}$ ) with large lumen, alveolar duct (Ad) and alveoli (A) (H\&E stain, X40).

(2) Respiratory bronchiole $(\mathrm{Rb})$ lined with simple columnar epithelium $(\mathrm{Ce})$ and cuboid Clara cell $(\mathrm{Cl})$. Alveolus (A) separated by alveolar wall (arrow) and smooth muscle (Sm) (H\&E stain, X100).

Figs. $(3,4)$ : Light micrograph of lung section of mouse inhaled gasoline 90 for 4 weeks showing:

(3) Inflammatory cell infiltrate (circle), cellular debris (star) in the lumen of respiratory bronchiole ( $\mathrm{Rb}$ ), emphysema (dashed arrow) and alveolar hemorrhage (arrow).Alveolus (A) (H\&E stain, X40).

(4) Enlarged part of the previous figure showing enlarged alveolus (A) with thin alveolar wall (arrow) and respiratory bronchiole ( $\mathrm{Rb}$ ) having columnar epithelium (Ce) and Clara cell (Cl) with irregular nucleus (H\&E stain, X100). 
Figs. $(5,6)$ : Light micrograph of lung section of mouse inhaled gasoline 90 for 8 weeks showing:

(5)Intra-alveolar haemorrhage (arrow), liquid infiltration (dashed arrow) emphysema (star) and thick alveolar wall (circle ) (H\&E stain, X40).

Fig. (6) Thick alveolar wall (circle) and respiratory bronchiole ( $\mathrm{Rb}$ ) with cellular debris (arrow). Alveolus (A), degenerated Clara cell (Cl) (H\&E stain, X100).

Figs. $(7,8)$ : Light micrograph of lung section of mouse inhaled gasoline 80 for 4 weeks showing:

(7) Region of perivascular inflammatory cell infiltrate (arrow), alveoli with emphysema (star) and congested respiratory bronchiole $(\mathrm{Rb})$ with exfoliated epithelial cells (circle) (H\&E stain, $\mathrm{X} 40)$.

(8) Dilated congested blood vessel (Bv), perivascular fibrous mass (star), thick alveolar wall ( circle ) and alveoli with emphysema (arrow) (H\&E stain, X40).

Figs. (9,10): Light micrograph of lung section of mouse inhaled gasoline 80 for 8 weeks showing:

(9) Enlarged respiratory epithelial fold (dashed arrow), dilated blood vessel (Bv) with stasis blood cells, perivascular inflammatory cell infiltrate ( circle ), alveoli with emphysema (star), thick alveolar wall (arrow) and respiratory bronchiole (Rb) contain cellular debbris (H\&E stain, $\mathrm{X} 40$ ).

(10) Thick alveolar wall ( circle) and thin one (arrow), cellular debris (dashed arrow) in bronchiole lumen (Rb), alveolus (A)and Clara cell $(\mathrm{Cl})$ with shrinked nucleus (H\&E stain, X100

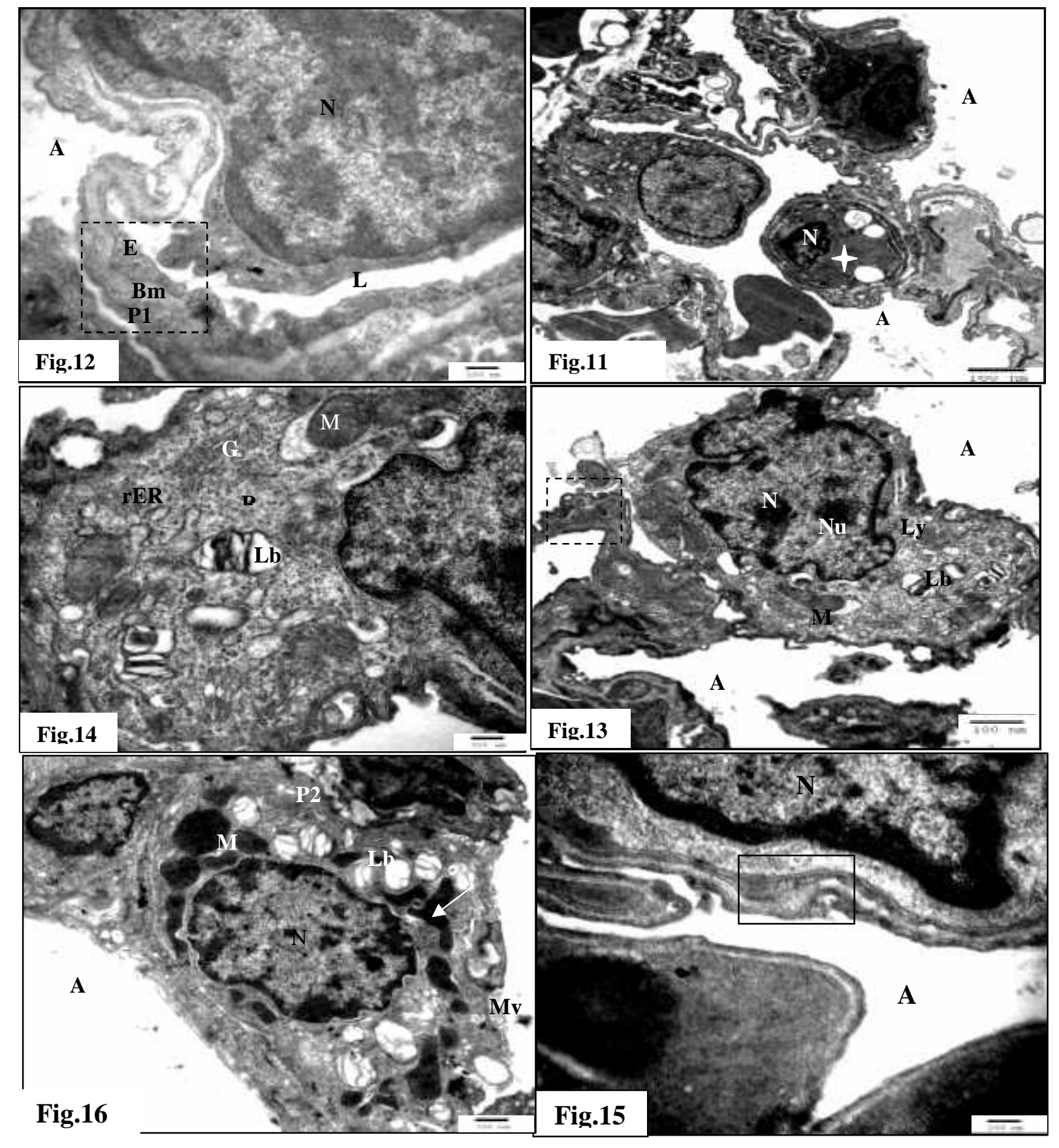


Figs. (11-14): Transmission electron micrograph of lung section of control mouse, showing:

(11) Alveolar wall between two alveoli (A), capillaries (star) made up the bulk of alveolar wall . The lumen of capillary includes the endothelial nucleus (N) (uranyl acetate - lead citrate stain, X2500).

(12): Attenuated alveolar septum ( square ) between blood vessel and alveolus (A) consisting of the cytoplasm of type I pneumocyte (P1), fused basement membrane (Bm) and cytoplasm of the capillary endothelial cell (E). capillary Lumen (L), dense endothelial nucleus $(\mathrm{N})$ (uranyl acetate-lead citrate stain, X10000).

(13): normal type II pneumocyte with cytoplasmic lamellar bodies (Lb), oval mitochondria (M), secondary lysosome (Ly), irregular large nucleus $(\mathrm{N})$ with disperse chromatin and prominent nucleolus $(\mathrm{Nu})$. Alveolar septum (square). A: alveolus (uranyl acetate-lead citrate stain, X7500).

(14): Enlarged part of the previous figure, showing oval mitochondria (M), lamellar body (Lb), free ribosomes (R), rough endoplasmic reticulum (rER), multigolgi apparatus (G) and part of the nucleus (N) (uranyl acetate-lead citrate stain,X7500). Fig. (15-18): Transmission electron micrograph of lung section of mouse inhaled gasoline 90 for 8 weeks showing:

(15) Thin alveolar septum (square), nucleus of endothelial cell $(\mathrm{N})$ with marginal heterochromatin and alveolus (A) (uranyl acetate - lead citrate stain, X10000).

(16) Increased number of lamellar bodies (Lb), , irregular nucleus (N) of type II pneumocyte (P2) with marginated heterochromatin.,microvilli (Mv), pleomorphic (arrow) and fused mitochondria (M) (uranyl acetate-lead citrate stain, X4000).

The capillary endothelium cell had elongated irregular nucleus with marginated heterochromatin and cytoplasmic invagination. The alveolar septum appeared thicker than control dueto the increase in thickness of both type I pneumocyte and of endothelial cell cytoplasm (Fig.20). The type II pneumocyte had increased number of destructed lamellar bodies ,pleomorphic mitochondria with broken cristae (Fig.21),folded nucleus with dilated nuclear envelope, short profiles of rough endoplasmic reticulum, mutlivesicular body and free ribosomes (Fig.22).

\section{Discussion}

In the present study, there was an increase in body weight of all experimental mice but the percentage body weight increase in mice treated with gasoline (90 and 80) was lesser than control mice. This result agrees with (Ahmed et al., 2011) who revealed a significant increase in the relative lung / body weight ratio. The increase might have been the result of the gasoline-induce histopathological changes manifested as accumulation of inflammatory cells, fibrosis and congestion of vessels and blood capillaries. In addition, the accumulation of appreciable amounts of amorphous materials and necrotic cells debris appeared in the bronchioles and alveolar regions, as revealed by the ultrastructural examination.

On contrary, rats exposed to ungraded concentrations of gasoline vapour (6h. /day) for 20 weeks showed weight loss compared to control(Uboh et al. ,2008). Also,Poon et al. (1995) reported that female rats exposed to gasoline vapour (3200ppm) six h. /day, five d. / w. for four weeks exhibited depression in body weight gain.

Al-Jahdali et al.,(2007) reported that guinea pigs exposed to gasoline vapor for 30,60 and 90 days in laboratory resulted in focalcollapse in the lung parenchyma, infiltration of inflammatory cells, intra-alveolar hemorrhage, blood congestion, disruption of alveolar septa causing focal emphysema, marked lymphoid aggregation within parenchyma, alveolar thickening with increased interstitial reticulindisposition, enhanced proliferation of bronchus associated lymphoid tissue,sloughing of epithelial cell increased mucosa secretion and elongation of epithelial folds lining the bronchus and bronchiolar tissue . Al-Saggaf et al. (2008) reported that guinea pigs exposed to gasoline vapor resulted in focal collapse in the lung parenchyma, infiltration of inflammatory cells, intra-alveolar hemorrhage, blood congestion, disruption of alveolar septa causing focal emphysema, marked lymphoid aggregation within parenchyma.

Abousalem et al., (2014) showed that the lungs of benzeneexposed rats revealed congested blood vessels, perivascular hemorrhage and edema. The bronchioles showed hyperplasia and desquamation of the lining epithelium. Moreover, squamous metaplasia was also detected. All these alterations determined in the present study which might lead to pulmonary injury (Domej et al., 2007).

The examination of lung sections from the 8 weeks exposed group revealed severe injury in the architecture pattern manifested as alveolar damage, shedding of bronchiolar epithelia and loss of cell membrane integrity, concomitant with intensive interstitial and alveolar infiltration with neutrophils. These results are most likely ascribed to excessive membrane lipid peroxidation and gasoline induced inflammatory reactions (Ahmed et al., 2011).

On the ultrastructural level, benzene inhalation caused blabbing of the alveolar cell membranes and degeneration of their cytoplasm and organelles. Moreover, the damaging effects reached the nuclei which appeared irregular. The type II pneumocytes were also severely affected with increased number of destructed lamellar bodies, irregular nucleus, pleomorphic and fused mitochondria . This wide spread cellular damage is likely related to the gasolineinduced impairment of the lung antioxidant defense system (Ahmed et al., 2011).As when the lung was exposed to various inhaled toxic products, the toxicity was mediated, at least in part, through the generation of free radical ( Pagono and Barazzone, 2003). The antioxidant system is the primary defense line against reactive oxygen species and lung tissues are protected against these oxidants by a variety of antioxidant mechanisms (Kinnula and Crapo, 2003). 
The ultrastructural results obtained, in this study revealed inner membrane structure which provides evidence of poor degeneration of mitochondria, broken cristae and deformed

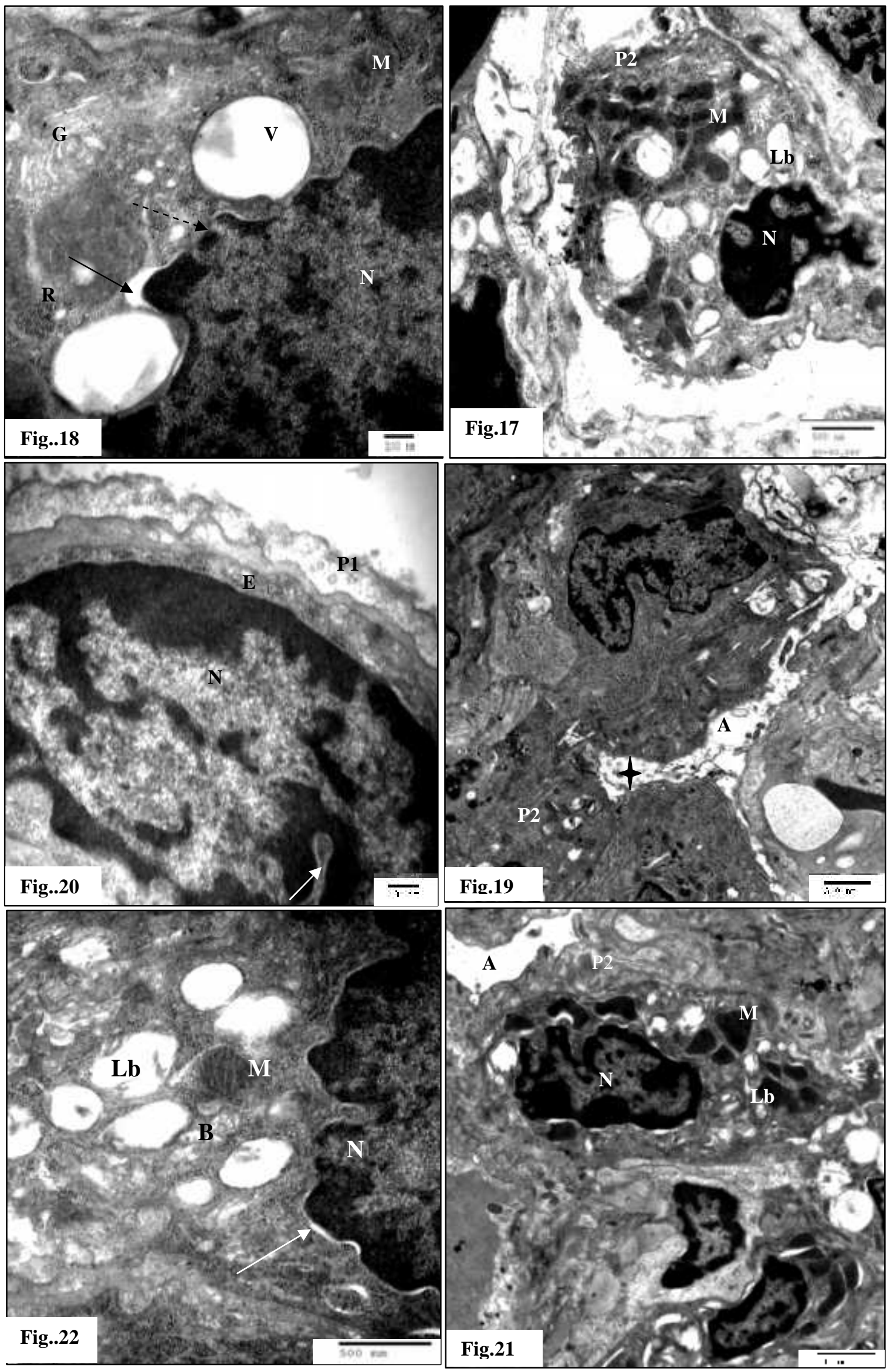


(17) Increased number of both destructed lamellar bodies (Lb) and segmented mitochondria (M) . Type II pneumocyte (P2) pyknotic nucleus $(\mathrm{N})$ with prominent heterochromatin (uranyl acetate-lead citrate stain, X5000).

(18): large part of type II pneumocyte showing hypertrophied Golgi apparatus (G), cytoplasmic vacuole (V), part of the nucleus (N) with wide nuclear pore (dashed arrow) and dilated nuclear envelope (arrow),dense mitochondria $(\mathrm{M})$ and free ribosomes (R) (uranyl acetate-lead citrate stain, X10000).

Fig. (19-22): $\quad$ Transmission electron micrograph of lung section of mouse inhaled gasoline 80 for 8 weeks showing: (19) Alveolus (A) filled with secretion (star) and type II pneumocyte (P2) (uranyl acetate-lead citrate stain, X3000).

(20) increased thickness of alveolar septum due to increase in thickness of both attenuated cytoplasm type I pneumocyte (P1) and the cytoplasm of endothelial cell (E), irregular nucleus of capillary endothelium $(\mathrm{N})$ with cytoplasmic invagination (arrow) (uranyl acetatelead citrate stain, X10000).

(21) Type II pneumocyte (P2) with increased number of destructed lamellar bodies (Lb), pleomorphic mitochondria (M) and folded nucleus (N). Alveolus (A) (uranyl acetate-lead citrate stain, X4000).

(22) Increased number of lamellar bodies ( $\mathrm{Lb})$ with indistinguishable lamellae, folded nucleus $(\mathrm{N})$ with dilated nuclear envelope (arrow) in type II pneumocyte (P2). Mitochondria (M) and mutlivesicular body (B) (uranyl acetate-lead citrate stain, X10000).

mitochondrial ability to produce ATP needed by lung cells (Ahmed et al., 2011).

It was found that fuel fumes have particles that are very minute ranging from $0.02-0.2 \mathrm{~nm}$ in diameter. They have greater surface area to mass ratio \& the fraction of toxic compounds, e.g. metal particles \& hydrocarbons is more as well; so they easily reach up to the terminal bronchioles invading the parenchyma causing chronic inflammation \& thus, leading to restrictive pattern of lung disease (Begum \&Rathna 2012).On contrary, rats and monkeys failed to exhibit any consistent adverse respiratory effects following intermediate-duration exposure to $1.552 \mathrm{ppm}$ gasoline vapors (Mann et al., 2002).

\section{Conclusion}

Gasoline vapor induced variable changes included the body weight and the lung histology, which increased according to duration of exposure. It remains uncertain what compound(s)in gasoline caused the observed harmful effects on pulmonary epithelium. Further researches would be required to determine what constituent(s) may be responsible for these effects .Also, perform more studies on car fuel station to compare between laboratory and station results.

In order to minimize the occurrence of such toxic effects of occupational exposure to benzene the following points should be put in considerations: i) continuous health monitoring of exposed workers through replacement and periodic health examination. ii) Regular determination of benzene concentration in the working atmosphere is of utmost importance.

\section{Acknowledgments:}

Our thanks to Electron Microscope Unite- Faculty of Science- Alexandria University for skillful technical assistance.

\section{References}

Abousalem,M.,Elgerwi,A. El-Mashad,A.(2014).

Genotoxic and histotoxic effects of air pollutants at a benzene station on albino rats. International Journal of Basic \& Clinic Pharmacology, 3 (1):144-150.
Ahmed, R., Nahed, H.,Riad,A.,Nagui, H. ,Hoda,G., Mabrouka,A.( 2011). Gasoline inhalation induces perturbation in the rat lung antioxidant defense system and tissue structure. International journal of environmental science and engineering (ijese), 1: 1-14

Al-Jahdali, N., Al-Saggof, S.,Mujalled, M., Shaker, S. (2007). Effect of Environmental Pollution with car fuel (Gasoline vapor) on histological and Histochemical Structure of Guinea pig.Respiratory Air passages and lung tissue.Masterthesis.College of Science, King AbdulAzizUniversity, KSA.

Alsaggaf, S., Mujalled, M., Al-Jahdali, N. (2008). Effect of car fuel on histological structure of guinea pigs lung and effectiveness of vitamin $\mathrm{C}$ in protection against histological changes. The $18^{\text {th }}$ international conference on environmental protection is a must;Alexandria -10-12 May Egypt, 241-250.

Ata, M. Hassan ,S. ,Hadi, H.(2012). Multi Organ Failure Following Intravenous Gasoline for Suicide:A Case Report ActaMedicaIranica, 50(12): 846-848.

Bancroft, D.,Gamble, M. (2002). The theory and practice of histological technique. $5^{\text {th }}$ edition. Churchil Living Stone. $75 \mathrm{p}$.

Begum ,S.,Rathna,M.B. (2012). Pulmonary function test in petrol filling workers in Mysore city. Pak J. Physiol. 8(1): 12-14.

Cutler,J, ,Cleveland, D.C., Washington,D. (2007). Health effects of gasoline .In:Encyclopedia of Earth:Environmental Information Coalition,NationalCouncil for Science and the Environment.

Domej,W., Mitterhammer, H., Stauber, R., Kaufmann, P., Smolle, K.H.(2007) Successful outcome after intravenous gasoline injection. J Med Toxicol.,3(4):173-77.

Grebic,D.,Jakovac,H.,MrakovcicSutic,I.,Tomac,J.,Bu log,A., Micovic,V.Radosevic-Stasic,B.(2007).Short-term exposure of mice to gasoline vapor increases the metallothionein expression in the brain,lung and kidney .Histopathol.,22(6):593-601

Kinnula, V. L. , Crapo, J. D. (2003). Superoxide gismutase in the lung and human lung diseases. Am. J. Respir. Crit. Care. Med., 167(12): 1600-1619. 
Lin,C.W., Chiang,S.B. ,Lu,S.J.(2005).Investigation of MTBE and aromatic compound concentrations at a gas service station.EnvironMonit Assess.,105(1-3):327-339.

Mann,W.J.,Muttray,A.,Schaefer,D.,Klimek,L.,Faas,
Pagono, A.,Barazzone, A. (2003). Alveolar cell death in hyperoxia-induced lung injury.Ann. N. Y. Acad. Sci., 10: 405-416.

Poon, R., Chu, I.H., Bjarnason, S.,Vicent, R., Potvin, M. ,Konietzko,J.(2002).Exposure to $200 \mathrm{ppm}$ of methanol M., Miller, R.B.,Volli, V.E. (1995). Toxicol And increase the concentrations of interleukin-1 $\beta$ and Health;11(3): 343-361.

interleukin-8 in nasal secretons of healthy volunteers. Uboh, F.E, Akpanabiatu, M.I, Alongwho, I.J., Ebong, Ann.Otol Rhino Laryngol.,111:633-638.

P.E.,Umoh, I.b. (2008). Effect of vitamin A on weight-loss

Monago, C. C.,Obidoa, O., Onwuka, F.,Etim, E. and Haemototoxicity associated with gasoline vapours (2011).Effects of Gasoline and Oxygenated Gasoline exposure in wistar rats. International Journal of Inhalation on Lungs and Trachea in Rats. Asian Journal of Pharmacology, 4(1): 40-45.

Research in Chemistry , 4( 12):1872-1876.

Ugwoke, C.C., Nwobodo, E.D., Unekwe, P., Olike,

Nagy,E. ,Noren, U.G., Zeisig, M., Ekstion, L.G., M., Chukwuma, S.T.,Amilo, G. (2005). The reproductive Moller, L. (2004). DNA adduct formation and physiological dysfunction effects of gasoline inhalation in albiro rats. effects from crude oil distillate and its desived base oil in Nigerian journal of physiological Sciences, 20(1-2): 54-57. isolated, perfused rat liver. Arch. Toxicol., 78: 144-121. 